www.jmscr.igmpublication.org

Impact Factor (SJIF): 6.379

Index Copernicus Value: 79.54

ISSN (e)-2347-176x ISSN (p) 2455-0450

crossrefDOI: https://dx.doi.org/10.18535/jmscr/v6i8.133

Journal Of Medical Science And Clinical Research

\title{
Evaluation of Dark Field Microscopy for the Early Diagnosis of Leptospirosis- A Prospective Study
}

\author{
Authors \\ Nitesh Kumar Jaiswal ${ }^{1}$, Binay Kumar $\operatorname{Singh}^{1^{*}}$, S Chandrasekaran ${ }^{2}$, Rohit Kumar \\ ${ }^{1}$ Department of Microbiology, Patliputra Medical College, Dhanbad \\ ${ }^{2}$ Department of Microbiology, NIMS, Vijayawada \\ *Corresponding Author \\ Binay Kumar Singh \\ Department of Microbiology, Patliputra Medical College, Dhanbad, India
}

\begin{abstract}
Background: Leptospirosis is a worldwide public health problem. Early diagnosis of leptospirosis is essential since antibiotic therapy is useful only when it is initiated early in the course of illness. The purpose of this study was to evaluate dark field microscopy for early diagnosis of leptospirosis.

Materials and Methods: A total of 81 blood samples were collected from the suspected patients. Blood samples $(5 \mathrm{ml}$ each) were collected aseptically in two sterile SV10 vials, one containing $500 \mu \mathrm{l} 1 \%$ sodium oxalate solution $P^{H} 8.0$ and another in dry tube. The former sample was used for dark field microscopy and the other was used for serodiagnosis by MAT and ELISA. Blood was also collected from 50 healthy blood donors and tested by DFM, ELISA and MAT.

Results: It was found that found that DFM sensitivity is 55.55\% (45/81), IgM ELISA is 65.43\% (53/81) and MAT is $54.32 \%$ (44 /81). On evaluation of DFM we found, its sensitivity is $61.64 \%$ (45/73), specificity is $95.23 \%$ (40/42), positive predictive value is $95.74 \%$ (45/47) and negative predictive value is $58.82 \%$ (40/68).

Conclusion: Sensitivity of DFM was found to be lesser than that of ELISA but slightly more than that of MAT. Evaluation of DFM showed good sensitivity and greater specificity. Hence DFM can be performed using a good dark field microscope and anticoagulant added blood for the early diagnosis of leptospirosis along with ELISA.
\end{abstract}

Keywords: DFM, Leptospira, ELISA, MAT, Spirochaete.

\section{Introduction}

Leptospirosis is an acute febrile illness caused by pathogenic species of the genus Leptospira. This disease has a worldwide distribution, but has the greatest impact on health in developing countries where it is often under-recognized ${ }^{[1]}$. Early diagnosis of leptospirosis is essential since antibiotic therapy is useful only when it is initiated early in the course of illness. ${ }^{(2)}$. Diagnosis at an early phase, however, is hampered by the non-specific presentation of leptospirosis. A number of diagnostic tests for leptospirosis are available, all of these test are aimed to detect specific antibody against pathogenic Leptospira ${ }^{(3)}$. During the early phase of the disease leptospires may be seen in a blood examined with dark field 
microscopy. Dark field microscopy involves collection of blood in liquoid (sodium polyanethol sulphonate) in sterile saline or sodium oxalate in phosphate buffer at $\mathrm{pH} 8.0$.Centrifugation of blood at $3000 \mathrm{rpm}$ for 5 minutes sediments blood cells and the supernatant can be examined under dark field microscope for leptospires by their characteristic morphology and motility. Dark ground microscopy from plasma after treating blood sample with $1 \%$ sodium oxalate solution in phosphate buffer is simple and economical which could be a good alternative method for early diagnosis of leptospirosis ${ }^{(4)}$. Pseudoleptospires can be seenin clotted blood ${ }^{[5]}$ or in blood added to broth for culture and incubated for one or two days and then looked for leptospires ${ }^{[6]}$.

In the present study we have performed DFM, ELISA and MAT on suspected leptospirosis cases and blood donors. Evaluation of DFM has been done with ELISA and MAT positive suspected leptospirosis cases as true positive and ELISA and MAT negative blood donors as true negatives.

\section{Materials and Methods}

The study was conducted between the years 2014 to 2015.A total of 81 blood samples were collected from the patients having the history of fever, severe headache, vomiting, myalgias, conjunctival suffusion, jaundice, stiff neck, stomach pain breathlessness. A total of 50 blood samples were also collected from healthy blood donors as control cases. The protocol was approved by Institutional Ethical Committee, Annapoorana Medical College and Hospital, Salem Tamilnadu. Patients showing positive test for dengue, malaria, hepatitis and enteric fever were excluded from this study. After taking verbal informed consent, blood samples ( $5 \mathrm{ml}$ each) were collected aseptically in to two sterile SV10 vials, one containing $500 \mu 11 \%$ sodium oxalate solution $\mathrm{P}^{\mathrm{H}} 8.0$ and another dry tube. The former sample was used for dark field microscopy and the other was used for serodiagnosis by MAT and ELISA. Data were collected as age, sex, occupation and exposure history of the patient.
Dark field examination (DFM): The freshly collected blood in sodium oxalate solution was centrifuged at about $3000 \mathrm{rpm}$ for 5 minute to sediment the cellular elements. The supernatant plasma $10 \mu \mathrm{l}$ was placed on a $22 \mathrm{~mm}$ square new microscopic slide. A cover slip was placed on the drop and pressed to form a thin film without air bubbles. One edge of the film was focused under binocular dark field microscope (Olympus CX-41) with the high power objective $(\mathrm{x} 400)$. The number of leptospires seen in about 100 high power field (HPF) was determined by simple counting and the report was given as Leptospira positive per HPF or per 100 HPFs depending upon the concentration. If no Leptospira was seen in $100 \mathrm{HPFs}$, the report was given as Leptospira negative.

\section{Enzyme Linked Immunosorbent Assay}

(ELISA): Leptospira IgM antibody was detected in the serum using PANBIO Leptospira IgM ELISA kit (Panbio-Alere, Australia). Standard ELISA procedure was followed as per the manufacturer's instructions. Optical density (OD) values were recorded in an ELISA reader by using $405 \mathrm{~nm}$ filters.

\section{Microscopic Agglutination Test (MAT):}

Microscopic Agglutination Testing (MAT) was done using the following antigens (serogroup followed by serovar in parentheses): serogroup Andamana (serovar Andamana), Australis (Australis), Bataviae (Bataviae), Canicola (Canicola), Cynopteri (Cynopteri), Djasiman (Djasiman), Grippotyphosa (Grippotyphosa), Icterohaemorrhagiae (Icterohaemorrhagiae), Pomona (Pomona) and Sejroe (Hardjo). Sera were screened at a dilution of 1:100 and positive sera were titrated to endpoint using standard methods. This was performed by mixing the test serum with a culture of leptospires and then evaluating the degree of agglutination using darkfield microscope. The end-point was evaluated for serum which shows $50 \%$ agglutination, leaving $50 \%$ free cells when compared with a control culture diluted 1:2 in phosphate-buffered saline. 


\section{Results}

Table 1 shows test results of suspected cases of leptospirosis using single blood sample

\begin{tabular}{|l|c|c|c|}
\hline Test & $\begin{array}{c}\text { No of positive } \\
\text { cases }\end{array}$ & $\begin{array}{c}\text { No of negative } \\
\text { cases }\end{array}$ & Total \\
\hline DFM & 45 & 36 & 81 \\
\hline IgM ELISA & 53 & 28 & 81 \\
\hline MAT & 44 & 37 & 81 \\
\hline
\end{tabular}

It was found that found that DFM sensitivity is $55.55 \%(45 / 81)$, IgM ELISA is $65.43 \%$ (53/81) and MAT is 54.32\% (44/81) shown in Table 1.

Table 2 Shows results of DFM, ELISA and MAT for the blood donors

\begin{tabular}{|l|l|l|l|l|}
\hline & $\begin{array}{l}\text { ELISA +/ } \\
\text { MAT+ }\end{array}$ & $\begin{array}{l}\text { ELISA +/ } \\
\text { MAT- }\end{array}$ & $\begin{array}{l}\text { ELISA -/ } \\
\text { MAT+ }\end{array}$ & $\begin{array}{l}\text { ELISA -/ } \\
\text { MAT- }\end{array}$ \\
\hline DFM + & 2 & 1 & 0 & 2 \\
\hline DFM - & 3 & 1 & 1 & 40 \\
\hline TOTAL & 5 & 2 & 1 & 42 \\
\hline
\end{tabular}

+ Positive, - Negative

Table 2 reveals result of DFM, ELISA and MAT for the 50 healthy blood donors. Only 2 samples were true positive as it was positive for DFM, ELISA and MAT while 42 were identified as true negative samples.

Table 3 Shows evaluation of DFM using true positive and true negative cases of leptospirosis

\begin{tabular}{|l|c|c|c|}
\hline & $\begin{array}{c}\text { True positive } \\
\text { cases (ELISA +/ } \\
\text { MAT+) }\end{array}$ & $\begin{array}{c}\text { True negative } \\
\text { cases (ELISA -/ } \\
\text { MAT-) }\end{array}$ & Total \\
\hline DFM + & 45 & 2 & 47 \\
\hline DFM - & 28 & 40 & 68 \\
\hline TOTAL & 73 & 42 & \\
\hline
\end{tabular}

+ Positive, - Negative

Table 3 reveals that the DFM sensitivity is $61.64 \%$ (45/73), specificity is $95.23 \%$ (40/42), positive predictive value is $95.74 \%(45 / 47)$ and negative predictive value is $58.82 \%$ (40/68).

\section{Discussion}

DFM was found to be more sensitive $66 \%$ $(162 / 245)$ than ELISA $39.6 \%(97 / 245)$ [10]. In the present study ELISA was found to have greater sensitivity than DFM and MAT. Other workers have reported greater sensitivity of ELISA $15.6 \%$ (74/473) than that of MAT $6.55 \%(31 / 473)^{[11]}$. Another study has evaluated DFM in comparison with ELISA and it was found that the DFM sensitivity $(60.5 \%)$ is slightly lower than ELISA
(79\%) therefore can be considered as rapid and economical test for the early diagnosis ${ }^{[8]}$. Sugandhi Rao et al found DFM to have a sensitivity of $27.27 \%(12 / 44)$ in cases of hepatorenal involvement ${ }^{[12]}$. We have observed DFM sensitivity of $61.64 \%$, specificity of $95.23 \%$, and positive predictive value of $95.74 \%$ and negative predictive value of $58.82 \%$. Evaluation studies have shown DFM to have a sensitivity of $40.2 \%$ (37/92) and 70\% (68/97) respectively by Vijayachari et al and Chandrasekaran \& Ganesan $[7,10]$. They have reported DFM specificity as $61.5 \%(48 / 78)$ and $62.4 \%$ (156/250) respectively. These findings indicate the need to compare with PCR.

We have found varying concentration of Leptospira per $100 \mathrm{HPF}$. The present study reveals that if the technique of dark field microscopy is standarised it can be use for the early diagnosis of leptospirosis. Earlier study has reported that DFM is the procedure of choice for the demonstration of organisms in body fluids ${ }^{[9]}$.

The diagnostic accuracy of DFM increases when number of leptospires is more in blood. This is useful when the blood sample is collected at early stage of the infection. Recognizing leptospires is difficult, when only small numbers of leptospires are present. In such a situation the process become technically demanding and need experienced person to perform this method ${ }^{[1]}$. Conventional dark field microscopes like Olympus CX-41, Nikon and Carl Zeiss should be used. Blood should be collected in liquoid or sodium oxalate at pH 8.0 so that plasma could be tested within 30 minutes to report the presence of leptospires in the blood.

\section{Conclusion}

The present study has shown the higher sensitivity of ELISA and DFM in the early diagnosis of leptospirosis. If both tests are employed the real burden of leptospirosis can be found. Early specific antibiotic treatment with Penicillin, Amoxycillin etc could prevent further complications involving liver, kidney, brain and eyes. 


\section{References}

1. World health organization."Human leptospirosis: guidance for diagnosis, surveillance and control" [book on the internet], world health organization;2003. http://whqlibdoc.who.int./hq/2003/2003/w ho_CDS_CSR_EPH_2002.23.pdf

2. Faine S B, Adler B, Bolin C, Perolat P. Leptospira and leptospirosis. 2nded. Melbourne, 1999: MediSci.

3. Kemapunmanus M, Sretrirutchai $S$, Khuntikij P, Pradutkanchana S, Pradutkanchana J. A prospective evaluation of four immunodiagnostic assays for human leptospirosis. Southeast Asian J Trop Med Public Health, 2004; 35: 863-7.

4. Sugandhi Rao P, Shashibhushan and Sivananda P G. Comparision of dark ground microscopy with serological test in the diagnosis of leptospirosis with Hepatorenal involvent - A preliminary study. Indian journal of pathology and microbiology, 1998; 41(4):427-429.

5. Hall M W. The occurrence of Spirochaetelike filaments in the blood of Dengue patients and in normal individuals. Am J Trop Med, 1925; 5: 307-15.

6. Smith T F, Wold A D, Fairbanks V F, Washington $\mathrm{J} A$ and Wlkowske $\mathrm{C}$ J. Pseudospirochetes, a cause of erroneous diagnosis of leptospirosis. American journal of clinical pathology,1979; 72:459-463.

7. Vijayachari P, Sugunan A P, Umapathi T, et al.Evaluation of dark ground microscopy as a rapid diagnostic procedure in leptospirosis. Indian Journal of Medical Research, 2001; 114: 54-58.

8. Sharma K K and Kalawat U.Early diagnosis of leptospirosis by conventional methods: One-year prospective study. Indian journal of pathology and microbiology, 2008; 51(2):209-211.
9. Gangadhar N L, Prabhudas K, Sashi B, Munasira S, Barbhuddhe S B, Rahman H. Leptospira infection in animals and human: a potential public public health risk in India. Rev.Sci.tech.off.int.Epiz, 2008; 27(3):885-92.

10. Chandrasekaran S and Ganesan S. Two criteria for the early diagnosis of leptospirosis and evaluation of darkfield microscopy (DFM).In: Souvenir of the $X X X V I$ National conference of IAMM held at India Habitat Centre, New Delhi 2012:130.

11. Agampodi S B et al. A Preliminary study on Prevalent Serovars of Leptospirosis among patients admitted to Teaching Hospital,Kandy, Sri Lanka. Indian J Med Microbiol, 2008; 26:405.

12. Sugandhi Rao P, Shashibhushan and Sivananda P G. comparision of darkground microscopy with serological test in the diagnosis of leptospirosis with Hepatorenal involvent - A preliminary study. Indian journal of pathology and microbiology, 1998; 41(4):427-429. 